\title{
Holocaust Survivors. A Study on the Poetics of Documentary Films
}

Images

vol. IX/no. 17-18

Poznań 2011

ISSN 1731-450X

The subject of this study is the poetics of seven fascinating documentary films whose heroes are people who survived the Holocaust. Following are the films in chronological order:

Kronika powstania $w$ getcie warszawskim wg Marka Edelmana, real. Jolanta Dylewska, 1993 (Chronicles of the Ghetto Uprising in Warsaw according to Marek Edelman, directed by Jolanta Dylewska, 1993).

Ocalona pamięta, real. Kary Antholis, 1995 (A Survivor Remembers, directed by Kary Antholis, 1995).

Pamiętam, real. Marcel Łoziński, 2001 (I Remember, directed by Marcel Łoziński, 2001).

Wyspa Getto, real. Ewa Żmigrodzka, Krzysztof Zwoliński, 2003 (The

Ghetto Island, directed by Ewa Żmigrodzka, Krzysztof Zwoliński, 2003)

Portrecista, real. Ireneusz Dobrowolski, 2005 (The Portraitist, directed by Ireneusz Dobrowolski, 2005).

Chłopak i dziewczyna, real. Sławomir Koehler, 2005 ( A Boy and a Girl, directed by Sławomir Koehler, 2005) .

Radegast, directed by Borys Lankosz, 2008.

The selection of the seven films above and the factors leading to my final decision have a personal and individual character, though not entirely subjective. It is a matter of course that the titles given here could be replaced with others just as worthy, considering that numerous films have been made on this theme. However, those which I eventually chose are characterized by a high level of typicality, which was not irrelevant in the decision-making process.

A question is raised at this point: do films about Holocaust survivors deserve their own separate genre? To this I would have to reply in the negative. If we are to use a thematic criteria, all the other earlier filmed accounts belong to a more general collection of documentary films about the Holocaust. It is undoubtable, however, that these seven films are connected together by more than the common theme of surviving the Holocaust. The connection is more subtle, belonging to a morphological deep structure of message and the commonality of the communicative form, which in the case of these films determines their common style and poetics. This assertion in no way claims to be the final word on the subject. It merely fulfills the role of a working hypothesis of our studies which, through a thorough analysis of the material, could be verified in the process of further deliberation. 
What, then, do these films have in common? It appears that the subtle character of their similarity does not lead to any one specific trait. The common element is the illusive character in the sense that it can be identified not on the „surface” of the medium but in the deep structures of each individual film. In other words, the common traits of the films can be identified on the various levels of values and constructions of a specific work. This involves not one but a series of traits connected with each other. With this claim I do not mean the mere sum of traits, but its own configuration. It is this which - strictly in relation with the theme - creates the similarities between the films and allows one to treat them as a single collection but not as a separate thematic type, nor as a separate film genre. Nonetheless it is a collection in which we can find a puzzling and intriguing unity in diversity. Our goal is to reconstruct and describe, point by point, the model elements which make up the specific message as well as the style and poetics of the documentary film whose hero is the Holocaust Survivor.

\section{A Signed Statement}

It is significant to note that in the documentaries that concern us the main role falls on the individual identity of the film's hero. In the central construct of every single one of these films we can find in each of them the personal testimony of a Holocaust survivor.

Gerda Weissmann, Marek Edelman, Jerzy Szapiro, Renata Skotnicka-Zajdman, Jerzy Płoński, Leszek Allerhand, Stanisław Jonas, Dawid Efrati, Henryk Mandelbaum, Wilhelm Brasse, Lucille Eichengreen, Erwin Singer, Roman Freund, Stella Czajkowska, Nachman Zonabend... All of them speak directly to the camera not only about themselves and their own lives, they also speak from themselves. Speaking about oneself of oneself, a direct transfer - this is a condition sine qua non for the credibility of the message and at the same time the fundamental aspect of the poetics of all of these films.

In any case, the narrative voiceover heard offscreen, when it is heard, fills merely a supporting role by serving the personal testimony of the onscreen speaker. At times it also happens that the narrator himself is seen onscreen. This type of narrator (as portrayed by Bronisław Wrocławski, who appears onscreen as a television reporter) guided Borys Lankosz through a reconstructed ghetto in Łódź in the documentary film Radegast. Though the scene itself was obviously set up, it is interesting to note that the intensity of the personal narrations of the survivors are in no way lessened by the re-enactment of their experiences. The actor who reads and interprets the words of Chaim Rumkowski turns out to be a fictional narrative character whereas the survivors are factual, authentic heroes.

It is thus just like in a real - in the sense that it is conducted according to the classic standards of behavior - court hearing. With the difference that the witness giving his testimony before a memorial court tribunal as an eyewitness to the tragedy turns out to be more than an ordinary witness-observer who saw and heard something by 
chance, standing at the sidelines and offering their assistance during the whole processs or event. The testimonies of individuals like Stanisław Jonas, Gerda Weissmann, Jerzy Szapiro, Marek Edelman, Dawid Efrati or Wilhelm Brasse are of considerable importance. Each of them, who were summoned to offer their testimonies on the matter, becomes a living evidence in the yet-unsolved case of mass genocide. Each of them is a witness who managed to escape from the grips of their oppressors. The intended victim who is not supposed to be among the living. Someone who has personally gone through the crime and who remembers it - a surviving participant of a tragic historical event who, after so many years, speaks of his experience for himself.

We are listening then to an account of the most personal form possible, which, in a case that has been going on for years, proves to be an invaluable testimony of the truth - material evidence of specific significance. Verba veritatis. Tragic events recalled from memory, words spoken by an old man, a Holocaust survivor, (profesor Jerzy Szapiro calls his unique status "life after life") become fiercely credible testimony. These words not only recreate history, they also mark it and confirm it through the undeniable personal testimony of their experience and participation. The distance maintained by the speaker forms a balance between his accounts of the facts and the terrifying words and images through which the crimes of the Holocaust were described and revealed.

A common element of the chosen film documentaries is the recurring or constant form of narration used by the heroes. Of the most unusual, often the most shocking experiences - their own and others' - they speak of them in surprisingly calm tones, hardly ever showing any sign of emotion. The indifference and apathy of the speaker play an important role. We remember the tears of Gerda Weissmann and the moment in which Wilhelm Brasse's voice breaks under the influence of immense emotion. Neither can one forget the unnerving scenes with Stanisław Jonas, his eyes brimming with tears and his jaw shaking with the memory of the overwhelming fear he felt as he hid and fled from the burning ghetto. It was then that, as a child in the act of self-preservation, he denied his Jewish ancestry and said to a stranger: "The Jews deserve to burn". A later scene has him recounting how, after an intense prayer to Jesus, he learns that his mother was released by the Germans.

In these scenes, however, we can observe that the expression of intense emotion serves as an exception. What is deemed normal or standard on the other hand is the restraint of narration displayed by the speakers when recounting their experiences and those of their loved ones during the war. This matter-of-factness leaves the impression not so much of an official testimony but more of a personal confession, a credible testimony to one's memory which has been relayed to others. 
As behooves a film documentary, the factuality of the accounts sustains reality and rejects the rhetoric ballast by relating directly about it. The fundamental form of the documentary film, in expressing immeasurable human suffering, aims to confront the silence of an indifferent world and its attitude of prosaic banality to widespread atrocity. This method of presenting the Holocaust corresponds on various levels with the style and composition of the films themselves. The one and the other, from the beginning up to the end, consistently operated on the method of "the poetics of the emotionally choked-up witness".

The Syndrome of the Unspoken
The authors and heroes of these documentaries stood before similar dilemmas. Could this be conveyed? Could it be accurately depicted verbally? Could the threat of those times be revealed?

The construction of documentary films about Holocaust survivors is based on the endless struggle between the spoken and the unspoken. The narrative goal of the survivors is speaking in spite of everything. In particular it is the recovery of one's voice through speaking. The memories released and redeemed by those who speak in front of the camera about the Holocaust is part of the process of naming that which is impossible to name. Speech sinks into silence. Each statement at each step is met by the barrier of the difficulty for adequate expression. Can one fully describe the menace of one's own (unconsummated) death? The fight for the life of the innocent man, whom the terrors of Nazism has forced to the limits of humanity, and who - thanks to his own will to survive and to the help of others - has managed to reclaim his humanity. With the passage of time comes another keenly intense imbalance which is difficult to overcome. On the one hand are millions of lives dismissed into oblivion, thrown into the abyss of total disregard. On the other hand are the few individuals left to their own devices, witnesses to unspeakable suffering and death.

The survivors of genocide live the life of one spared by destiny, a life after death. They speak of it matter-of-factly, touching on countless details spurred by memory. The stories contain no fascination, unless it is the expression of the inner desire not to die in silence. The act of speaking itself does however carry with it the pain of remembering, releasing, naming the hours, days, months and years soaked with unimaginable cruelty spent among wild beasts. They carry the incomparable suffering of would-be victims who managed to escape the inescapable, inevitable approach of merciless death. The narrator is a link, a guide, who takes us through the gateways of the land of the dead.

It is difficult to look at oneself. The story being told draws the participants into other circles: those that have already been told and those that still need to be told. The speaker and the addressee of the narration, the author and the viewer, trace and follow one after the other the vestiges imprinted on modern society, crossing common 
borders of today's world. All of the prints found constitute proof of the presence of the vanished.

Mortibus vivimus - we live with the dead. The accounts from the times of the Shoah represents the opening of graves, a symbolic exhumation, an uncovering of the world which was completely annihilated and which could no longer be revived. What are left are places in the world such as the center of Warsaw, a city completely destroyed by the war and inadequately rebuilt after it. Jerzy Płoński in the documentary Chłopak i dziewczyna, while visiting the football field of Skra, remembers how this was the location of the mass grave of thousands of victims. The inner space of memory. The concrete is revealed to be not so concrete after all. The recalled details do not show the whole, they only allow the memories to be evoked, called to mind. Half-a-century later, when the film is produced, almost nothing remains of the details and specifics of that age. Nothing except memory.

Film documentaries with the participation of Holocaust survivors do not rely on the replication of the threat of mass extermination. The screen presentation do not replace reality or function in its stead. The goal is not one hundred percent accuracy of representation. The whole does not play out in a clear setting. Light and shadow, in episode after episode, scene after scene, deal with the presented accounts and stand in opposition with each other successively. Light and shadow are not obvious. That which is unseen, unspoken, silenced, impossible to communicate - becomes an area of secrecy. Like the darkness in an artist's work, it gives it a depth, making it mysterious. The speaking hero and his audience establish contact and attempt to penetrate into the past, to read into its countless tracks, and to work like hunters in tracing the prints to reveal the path. This is how we see the Holocaust, through the clues put together and captured by the camera through our journeys over time. The knowledge of the narrator and the desire of the viewer to discover the unknown are combined in the film to form a new quality of narration. To see and to know.

The magical power of cinema has assured the endurance of those who survived and who, at the decline of their lives, want to preserve the memory and the truth about the Holocaust. From an anthropological point of view, documentary films about Holocaust survivors constitute a specific form of conveyance of extreme experiences. Each individual, and society at large, are the targets of this message. The filmed account becomes a testament to extreme experience. Experience which is borderline and traumatic and could in no way be eradicated. We cannot forget - it is imprinted on us for always. "I am hiding all the time - says Stanisław Jonas - and even when I am not hiding, I am in a way still hiding."

The first barrier for the speaker is therefore the inner block hidden in the inability to speak about traumatic experiences. Repeated 
probes at stirring war traumas result in the absolute inexpungibility of personal suffering and fear, that pain hidden and strangled within for so many years will resurface if silence is not maintained. The extremes of personal experience which the Holocaust survivor carries within himself likewise results in a fear or a doubt of the credibility of his own narrative. "Dichtung" (fiction) begins to cloud "Wahrheit" (truth). The described events appear too improbable, their circumstances unclear, incomprehensible and simply inconceivable. Cinema to some degree seems to annex and absorb reality.

Another difficult question is raised regarding the limits of sincerity that could be expressed in front of the camera. After all, the discussions revolve around the finality of their conditions. How far can we go in the revelation of the monstrosities of humanity and of the world? Monstrosities which they have personally gone through? How does one speak about all this? What does one convey? How does one not fall into banalities, into publicized simplifications, into moralizing tones, unwanted pedagogy, a martyr complex? How does one convey that which one has gone through without turning it all into "cinema"? How much of the crimes of the oppressors presented not as screen fiction but as a film documentary could be bourne and processed by the modern viewer? How does one avoid fusing screen spectacle with real life? There is also the fear of reducing the scale or importance of the widespread suffering of millions of victims through self-promotion and by yielding to the pressure of the pervading social matrix.

The documentary, sometimes called film of facts, is not, by any means, a guarantee of the true image of the world which it presents. That which is subjective does not suddenly become objective through the camera lens. However, the world undergoes an objectification and verification in the sense that communicating through the medium of moving images has a bipolar intersubjective character. The exchange of perspectives that we are dealing with here allows the authors to design their own points of view and gives the viewers the chance for a critical interpretation of the contents of the message. A question thus needs to be raised at this point: how does this exchange proceed in the case of the group of films named in this study?

Face to Face

In documentaries with Holocaust survivors the face to face technique serves as a cornerstone of the meeting that takes place onscreen between the hero and the viewer.

The recipient of the film has a unique occassion to develop a very personal contact with the man whose private story - told personally and in real time to each individual viewer - is seen from up close on the screen. The act of observing the speaker's face plays an unusual role in the process of watching the film. The speaker is often filmed from the front, in full lighting or artfully half-lit. It is not only his words that count, but each reaction, each moment and each minute detail. His glances and the expressions seen in his eyes are particular- 
ly effective in conveying meaning. A film set constructed in this way forces the speaker to either focus his eyes directly ahead or to glance to the side, these looks alternating with each other throughout the entire narration. Both the direct glance - with the speaker looking directly at the camera lens - and the intense close ups result in a whole screen experience of a very high level of intimacy.

In reality, this level of intimacy would be highly improbable with an individual one has just met. The closeness in this type of documentary film is both literal (with the use of a certain type of camera angle) and metaphorical (in the sense of an unusually intimate contact with another individual) and ensures that, for the viewer, nothing else matters for the remainder of the narration. In one moment a stranger in front of a camera becomes an intimate acquaintance, who, often after years of silence, reveals to us the secret of his life. A secret which is often unpredictably painful in its consciously terrifying details, at other times incomprehensible, leaving the viewer in awe - whether at the absolutely unexpected sequence of the remembered events, or at the shocking narrative.

That which touches us the most is the undoubtedly truthful solidity of the screen presentation. The words and images that reach the viewer become facts that appeal to the imagination. Their fractionality, their unavoidable divisiveness, their unintended incongruity often lead to the breaching of the linear course of the narration, excluding chronological objectivism. The films, for instance, are filled with various digressions. The order of narration mixes with the chaos of the narrated experiences and situations. As such, the imagination constantly deals with the unimaginable - the "I Remember" with the "I Don't Know". In the cultural space the act of communication intrudes into the cummulation of tension which affects both sides of the discourse.

The unprecedented feats of engineering and machinery designed for violence and mass killing which was built and perfected by Hitlerism are received differently when the dry facts and statistics are cited and when they are described by a would-be victim who managed to escape. This individual perspective, aside from undoubtable advantages, nevertheless also has a certain basic fault: it narrows the pole of vision, limits the image to the lens of a single experience. The speakers are aware of this. They speak solely of their experience, of what they personally went through. This is the reason for this form of narration which effectively protects the survivors from the tendency to generalize.

The lives of the survivors during the occupation go beyond the most fantastic fiction. How could one possibly survive all of this? Why am I chosen to survive, while others had to perish? Improbable, and yet possible. Ghostly verisimilitude, which at every step rejects a rational judgement of events. No-one, not even the most imaginative screenwriter would dare to come up with equally mad, improbable, 
blood-curling ordeals of the man escaping the grips of annihilation. The awareness of the viewer listening in on the story-telling is attacked by a flood of inexplicable oppositions and paradoxes.

Formally speaking, the accounts of the survivors are monologues. In the deep structure of communication, each of these monologues turn out to be internal dialogues. This has a great influence on how it is received by the viewers. From start to finish the dialogue form fills and organizes the structure of the message. Thanks to this the viewer does not remain a passive listener but comes into the role of a receiver who ought to independently look for and expect his own truth along with the hero of narrative. This refers not only to the stream of narrated events but also to the manner of their presentation - a manner which does not avoid disagreements, does not attempt to provide prompts to things which will always remain hidden between words and images and will always remain vague, incoherent and littered with blank spaces - inexplicable and secretive to the end.

The complex process of revealing the truth. The polarity of oppositions presented onscreen are collected, supplementing each other, gathering force. In the deep structure of discourse the multi-level interdependence between ethics and poetics makes itself felt. Both aspects connect and intertwine, mutually absorbing and disappearing into each other. The documentary form calls attention to its role in the presentation of the truth. The hero tries to describe and name the threat of what he suffered through, tries to find the right word for it. The narrative about the meanderings of his survival would not flow fluidly or smoothly. It would naturally cause some difficulty. Words would turn out inadequate. The plots thicken and become more complicated. In spite of everything the scars from the Holocaust continue to appear and develop on camera. The hero speaks on, though moments earlier in attempting to express the inexpressable says, "This cannot be described for anything in the world."

The narrative composed of inexplainable events and paradoxes. It is accompanied by trouble-filled dissonance. There is conflict and confusion of thoughts and feelings both on the side of the speaker and of the viewer. There is no relief, no happy endings, no clear morals or easy solutions. Internal conflicting sounds and the ambivalent character of everything which contains this relationship, remains an integral part, creating in its reception occassionally unbearable emotional tension. The world of the ghetto as a closed space from which the only exit is death. The incomprehensible paradox accompanies the discovery that threats equally dangerous haunt the fugitives outside the walls of the ghetto. This is why some fugitives, in an act of desperation, decided to return to their prison from which they had recently fled.

The bitterness of the saved. The price for being saved has to be paid in full throughout their whole lives. Feeling lost in the present, they also fear the prospect of the past returning. The state of being uprooted. Divided identities. The return to Poland and to the memo- 
ries as a cruel method of self-therapy. The awful alienation of Holocaust survivors. Traumas and guilts. The lifetime state of being suspended between today's events and yesterday's sufferings. The obliterated borders between the world of the living and the world of the dead. The unsolved puzzle of the Great Screenplay which tortures the psyche. Why me? Renata Skotnicka-Zajdman: "All survivors are guilty of this, that they survived, while others didn't." The heavens remain silent. Where was God at the time of the Shoah? Renata Skotnicka-Zajdman: "God was on vacation. I am looking for Him because I want to give Him a piece of my mind, take Him to court." Jerzy Płoński: "God has the right to test His sheep, but to what limits could these tests go?"

There is the tension created by the mystery of one's own survival - a mystery which is close to a solution and yet remains frustratingly impenetrable. Jerzy Płoński: „It is not a matter of courage, it is a matter of the sense of observation, of enduring." The young person's struggle to survive in the wake of constant death and all-pervading extermination. Fear and Hope. To constantly believe that one has a chance. Power and helplessness. The triumph of barbarism. Absolute violence and the cruelty of heartless executioners. The victims' lack of defences. Living human beings caught in a trap. The panic of instinctive escape. Paradoxical behavior. Unheard-of physical reactions. Godliness and godlessness. Faith and faithlessness. The feeling of betrayal towards one's loved ones and towards all those who perished. Terrible ethical choices. Jerzy Płoński says: “To this day I don’t know if I did the right thing" - he left his parents and siblings in the ghetto in Otwock. They are also often reluctant participants in the extermination process: the stoker incenerating corpses acting as the concentration camp photographer in Auschwitz, the young doctor in a Stawki hospital deciding who gets treated while those who had no chance of survival will be driven out of the Umschlagplatz and into certain death. A moment of silence, inward weeping, dumb despair, eyes turned away from the camera.

The survival instinct. The potentially fatal threat posed by other people that one meets: a German patrol, the Jewish police, a Polish szmalcownik (a Pole that blackmailed or denounced the Jews for money). There are those that denounce and there are those that help. Noble people who risked their own lives and the lives of their families by helping fugitives: Stefan Petri, Staszek from the Praga district of Warsaw, a German prostitute in Lwów and an unknown woman in Swidra who hid a runaway in her own apartment. The obscure identities of potential allies: salvation from the hand of the enemy, or an unexpected blow from one's own. ("Those szmalcowniks were actually good people" - says Stanisław Jonas cryptically as he bursts out laughing.) The field of survival which at one time has been shrinking, once again stretches out. The cemetery becomes a hideaway, and a tomb becomes a refuge (Leszek Allerhand after getting out of the 
Lwów ghetto says, "I had never felt so safe as I did in a stranger's grave"). Hellish memories from the ghetto and the recollection of the world before the war: sweets bought in Nalewki at the Saski Gardens, the education of a young Jerzy Shapiro at the Żoliborz High School (recalled without sentimentality or idealization as exemplified by the memory of his high school friends, who came back from vacation only to refuse to shake the hand of their Jewish colleague) and studies at the Medical Academy (recalled with searing pain at the school's own form of the classroom ghetto, separating the Jewish students from the rest of the class).

A question vital to the documentary form is borne regarding the verification of these collections of memories. The all-purpose key is the credibility of the realities. The concrete in the accounts of the survivors fulfill a major role: they evoke the dramatic past, they put to scale and verify frayed recollections. The heroes' memories, made available to the viewers, are planted and allowed to bloom in recalled details: the topography of the streets, gates, stairways, basements, attics and apartments, trajectories of escape routes, labyrinthian hiding places. The mozaic of memories constantly evoke new realities of dramatic events and their conditions. The truth, disabled and flawed, achieved with difficulty and experienced personally is available to the speaking hero. Each reflex of the mind, even the smallest recovered detail, is important. Nothing should be forgotten.

Individuals ("Rubinstein, the wise madman of the ghetto", Staszek from Praga, the dead Jewish insurgents who Marek Edelman today recalls only by name), objects, souvenirs, sounds, smells, details... Barbed wire, arm bands with the star of David, the hit song Fabryczna dziewczyna sung at the Litzmannstadt Ghetto, a Scout cap, a cardboard baggage - marked Hamburg which belonged to German Jews who were moved to Łódź and which was later used to cover the glass over the door of their new miserable apartment - discovered in the course of a local visit with a camera crew - a sewing machine, saccharine, a pension house in Otwock, Pomorski sweets, books from the library, a foot-bridge built by the Germans over Chłodna and a gate which briefly opens connecting the small and the big ghettos, the stink of the canals, a bath and a bed with white sheets for a dead-tired fugitive, a cupboard with two shelves into which a mother shoves her two children shortly before giving herself up to the Germans.

The characteristic sign of these recalled realities is dependence on two time-space dimensions. The room under the roof ("I was in this room" - says Renata Skotnicka-Zajdman). Canal manholes by Freta street ("the same manhole" - notices with wonder Jerzy Płoński). The high, almost three-meter walls of the ghetto still remain standing to this day by the streets of Grzybowska, Sienna and at the yards near Złota. The Warsaw streets of Nowolipki and Bonifraterska where we now pass through used to run along the length of the walls of the ghetto. From the wall of the corner building on the intersection of Chłodna 
and Żelazna, which survives to this day, would come shots aimed at Jewish passersby made by the sadistic psychopath of the Warsaw ghetto Josef Bloesche, also known as Frankenstein.

The accounts of those that survived the Holocaust compose a credible message of authentic experience in its clearest and most extreme form. Each of these accounts reveal complex interpersonal agreements, personal problems and experiences. They are not banal clichés made up of simplistic stereotypical images and lectures from school textbooks about history. I would like to stress on the complexity of the narratives in films about survivors. The events described in them are so credible and true that at times they seem improbable due to their extreme character. The film documentary in this form becomes almost hypnotically suggestive, achieving an intensity of form which is usually found in fictional cinema. We say in such moments - that's incredible, that's practically impossible. And yet it is possible since it did happen. It would be hard for us to believe in it all, were it not for the fact that the speakers are the same heroes that went through the same events that they are describing, testifying to the truthfulness of their experiences with their personal participation.

There is more to these words, however. A spiritual power breaks through, a personal freedom, an assertiveness and the feeling of inner independence that is characteristic of people who survived the Holocaust. One is impressed by their courage to publicly speak about the truth of what happened. The truth which contains the incredible, surprising complexity of the world and the importance of unique events which had led to someone's life being saved. The truth is revealed in its boundless ties with reality, though it might be interpreted as inexplicable and therefore "improbable".

Truth not as the "perfunctory", generally-accepted, created-forpublic-consumption copy which would be used as the official version. And not spoken ad hoc, a momentary quarter-of-a-truth or half-truth (read: a lie), but the whole truth, and nothing but. Without considering how that painful truth - uncut, uncensored, free from any limits or boundaries - might be seen by other eyes as surprising and unacceptable. But also politically incorrect, freed from illusions, assertive and rebellious in the sense of one's own act of crossing the lines against that which is allowed and what should be thought or what should be said. Believers, as well as non-believers of the witnesses of those hecatombs are thought to be going through their own confrontation with the threat of the Holocaust. The question "Where was God when millions of innocent people were being murdered?" also doubles as an expression of their opposition to attempts at the "familiarization" of the truth about the Holocaust, even by those who would find comfort in religion.

Stirring up taboos in the accounts of the survivors sometimes is in accord with what is generally accepted and what most people are 
ready to consider regarding this topic. For the sake of the truth and the sake of hope that it will "never again" happen, the speaker is allowed to question and reject cliches about the Holocaust abounding in social circles. He is also allowed to be incorrect (politically, ideologically, etc.) in the hopes that "never again", that the modern world - regardless of its various imperfections and in spite of everything - will be bale to prevent a "repeat". In this sense each of these narratives, without forcing anything on anybody, discreetly and without pressure, fulfill the role determined by the hero and the author of a well-understood method of persuasion[1].

The truth relayed in this way often turns out to be reprehensive and inappropriate, absolutely unacceptable to all those who lack the humility to receive it as it is. The rejected reality and the terrible past return in these accounts with doubled power. The man saved from the Holocaust does not seek any convenance. He knows quite well that propriety regarding the Holocaust is highly suspicious and threatening. In the name of truth (read: the whole truth) he chooses impropriety.

The "impropriety" referred to here is improper or incorrect in a specific sense. It reduces lies to dust. It is resistant to attempts to transform it by politicians and dogmatists. It tries to preserve the truth saved in his own memory about his own suffering and experiences. The widely expanded narration from episode to episode reveal the unexpected aspects of human behavior in the face of Extermination. In speaking publicly on how things were and what happened then they also accuse the world of inhumanity by allowing mass genocide to happen. The truth also refuses to submit to anyone and anything that might limit and censure it. This stance of the speakers gives their accounts lasting value and great worth.

The real truth. Independent, self-sufficient, free from any and all ideology, cleansed of bias, heedless of the unrehearsed eloquence of memory, or of the nobility of its form or even of its morality. The individual microhistory of a man's struggle for survival lacking claims for any form of generalization. This is not about another rival version. The only goal is to personally testify about the truth. Each art form has to deal with the difficulties of its expression and the form of its transfer. This truth, as imagined by Jerzy Ziomek, becomes the basic problem of poetics.

The experiences of the man rescued from the Holocaust are not ready novels. It is not easy to speak about it. A lot depends on the manner of speaking and the motive for his declaration before a camera. The voice of the survivor, his direct narrative preserved in the form of

[1] Theodore W. Adorno was clearly right when, in his excellent essay Wychowanie po Oświęcimiu (Education after Auschwitz) in 1966 (translated by J. Zychowicz into Polish in the monthly journal
„Znak" nr 285, 1978) came to the conclusion that it makes sense only as instruction for critical self-reflection. 
a film documentary constitutes a lasting clue, an enduring act of revealing that which really took place, what actually happened. Along with the profound message there exists an inner logic through which they achieve its important goal. The truth preserved on tape about the Holocaust, about the monstrosities that occurred, cannot be silenced, or changed, or forgotten. It ought to be remembered for all time. This is the voice of a living witness - spoken today, describing yesterday, directed towards tomorrow. The voice which never fades. In contrast with a testimony, it could never be retracted.

Each of these narratives contains for us a capital meaning not only as a personal testimony of the truth but also as a signature on the attendance sheet, a sign of existence and survival. The gesture of the would-be victim - shocking testimony of one man who escaped Hitler's death machine and avoided extermination, and now (in the Eternal Now with which cinema has gifted us) speaks to us, contributing to our presence its own priceless testimony. The open book of experience. That voice is like a constant and unsilenced protest against fossilization, negating and opposing death and nothingness.

The testimonies of survivors has an individual character, coming from a concrete individual, which means that the message, no matter how truthful or sincere, by its very form is subjective. The message which has a status of a court testimony. There is no possibility here of complete objectivity, nor should there be. There can neither be an absolute, complete awareness of everything that happened. In fact, quite the contrary. Speaking about one's and others' fates during the Holocaust is an attempt to get to the deeper layers of the tragedy by remembering and recovering the events. This memory to this day is painful and traumatic. This is the speaker's gift to the viewer - a generous and unusual gift of allowing him to assist in piecing together the stories of a witness in a fascinating court trial taking place onscreen. In this way both the speaker and the viewer participate in establishing a current perspective of the distant past and actually getting closer - if it is at all possible - to the truth of what happened.

The accounts of survivors complement and at the same time widen the dimensions of the modern world about the pain-filled memories of 20th century history. They do not allow today's world to forget about itself, its own heritage, and the terrible inheritance from the past. A crucial element of these accounts are the questions: how was it possible? how could it happen? Along with these questions is the unrelenting sensitivity and constant anxiety about new forms of intolerance, new forms of xenophobia, divisions among people, ethnic prejudices, and the propagation of hatred towards others.

The voice of experience is a narration unhurried and attentive. Its rhythm makes focus possible and removes the viewer from the chaotic, tumultous plurality of shallow and banal impressions which is provided by the noisy modern culture in its popular form. Speaking about the years of hunger and suffering in the ghetto, the daily pres- 
ence of death, the forced removals, the concentration camps, the gas chambers and mass extermination demands from the speaker and the listener keen attention and becomes a form of contemplation, a controlled plummeting deep into one's self, registering the contemporary echo of the past. In this sense the film narration with the participation of the survivors fulfills its role of persuasion, but certainly not that of manipulation.

Handle and Manipulation
In the ideological form of Western European and American reflections, film as a medium of mass communication has long ago crushed a certain dogmat. From the 1960s there has been an orthodox assertion that the manipulation of film material constitutes a vital and supposedly unavoidable trait of the medium. A general obligatory rule or total nonsense? What are we dealing with here? Where does this seemingly pervading but basically false idea come from?

As it might appear, this is the result of a hasty, uncritical acceptance of a widely acknowledged axiom of false logic. Based on the idea that each documentary reports and makes use of certain techniques such as narrative figures, framing, setting up a scene, camera angles, cuts made in the editing process, one can make the mistaken assumption that all the techniques used in documentary films automatically mean that some kind of manipulation is at work. This false assumption became another source of misunderstanding.

Distinguendum est. Let us attempt to solve this difficult problem once more, considering all of the following:

Firstly, the mere presence of film techniques, its participation in a documentary, does not necessarily mean manipulation, nor does it prove its presence.

Secondly, manipulation - defined here as a measure which is in its nature the abusive human act of falsifying reality - is in no way an inseparable element of the film medium.

Thirdly, each cinematic message contains in itself a process of creation (with the use of film techniques). Filmmaking is none other than the use of techniques - first in the filming process, and later in the editing room. The choice of a certain frame and its use in in the context of another frame: coming previously and after it. Without this necessary minimum in the form of choices and combination of visual signs and audial which appear onscreen, no film would be able to exist, function or carry their own meaning.

Fourthly, film techniques (such as, the shooting of a scene, the arbitrary stylistic figures, metaphors, metonimes, parallelisms, editing transitions, narrative figures, compositional set-up etc.) are based on the decisions of the author (producer/director/creator) as a definite organization of the film materials whose intended goal is the transfer of specific information.

Fifthly, the manipulation in cinematic transfer is not the use but abuse of film techniques used for the aim of falsifying the presented 
image of reality. It is not the camera and it is not film which falsify the screen image of the world. The author of the manipulation is human each and every time.

It follows that while film technique in itself is not a source of falsification, neither is it a guarantee of truth contained in the moving pictures. On the other hand, a totally "clean" documentary film free of any film techniques does not and cannot exist. In the process of visual or audiovisual communication, they are simply more or less "transparent". This is a matter of specific presentation and individual strategy used by the author. In the case of the former, there is the effect of the "non-presence" of techniques, which means that the viewer is not conscious of its use and is not aware of its presence. Nothing more.

Another conclusion: the identification of manipulation (read: the semantic overuse committed by the author of the film in the process of social communication) does not happen by itself without reason. This is the result of a critical reading of the message by the viewer.

The inclination for criticism is not something universal or widely apparent. We are not born with it, and it does not exist ex naturabilis. It is created ex usu, from learned habits; it is a specific ability which can be controlled and formed. Criticism has an individual character and depends on the degree of awareness as well as the individual textbook participation of the viewer. A necessary condition here is the appropriate level of linguistic competence which involves a basic familiarity with film discourse, a practical knowledge of the syntax of moving pictures, and a personal ability to read and interpret them.

Therefore, it is necessary therefore to clearly differentiate the presence of various media of communication in the various levels of film construction from their manipulation. The mere identification of the film techniques used in a documentary does not determine if what we see is a discourse between the author and the viewer or if it is manipulation. Manipulation does not have to be importunate and intense; manipulation skillfully disguised has often been proven to reveal upon closer inspection a high level of calculation and perfidy. The use of film techniques is strictly connected with the rhetoric of the language of moving pictures. In the communication process in depends on the determination of the level of intensity. The real problem is not in this case the rhetorical function of one or other form of techniques but on the scale of their overuse, allowing the author to manipulate the message.

It is worth noting that specific film techniques have their own conventions - serving as the carrier of meanings of the arbitrary elements used in the film. They are, a priori, neither good nor bad. In the process of social communication what matters is defined use: fair or unfair, ethical or unethical (that is, manipulative), serving the truth and achieving it or, quite the contrary, falsifying the screen image of reality.The improper use of techniques becomes a ploy, a trap set for 
the naive viewer, a tool for the vulgar or the sophisticated manipulation of his conscious thought or subconscious.

In considering the use of the words "consciousness" and "subconscious" in the context above, I actually had in mind that dark and irrational part of the brain that is the nonconscious, the ignorant. The fact that we see and hear something does not mean that we correctly understand the sense of a given message. Communicating in the language of moving pictures does not in any way guarantee comprehension. In fictional cinema and in documentary films, it is easy to instrumentalize the subject of the Holocaust. This observation touches in equal measure the author and the viewer. The unaware viewer of the film is particularly prone to and continually in danger of manipulation by the message. We can be protected from the author's manipulation by one thing: a critical reaction to the message. This would exclude interpretations of the work that are naive and indiscriminate.

In the case of the documentary film, its critical reception by the viewer is determined by a measure of limited trust and the constant confirmation of the credibility of each element and technique observed in the film.

For the Good of the Film
It is evident that film techniques have an arbitrary character. The repertuar of techniques created and constantly evolving in the one-hundred-year-old existence of film is rich and varied. It includes: stylistics, composition, geneology and rhetoric of audiovisual communication in the language of moving pictures. The aim of all these techniques is the same: they appear in various conditions of creation, serving the organization of its meaning. They cannot be created from the beginning. In the cinematic culture of a given time and place they co-exist and compete with each other and with numerous other means of communication (ways of presenting, motifs, stylistic figures, tropes of semantics, editing figures, types of narrators, variations of narration, compositional arrangements, types of films, genres, sub-genres, etc.) The statement above refers to all documentary films. They differ from each other not only through the presence of film techniques but in the "density" of their appearance as well as the semantic function that they fulfill. An example that we can cite at this point to clearly illustrate this case refers directly to the documents on people rescued from the Holocaust.

In the audiovisual documents collected from 1979 by the Fortunoff Archive (with its headquarters in Yale), and on a larger scale from 1994 by the Survivors of the Shoah Visual History Foundation founded by Steven Spielberg - respect an agreed-upon model and standard realization. It refers to the form as well as the content of the records. The obligatory standard of their poetics is determined by a far-reaching conservation and conscious reduction of medium of film expression, and what come after it - the ascetism of the message. The video camera, the standard format of images, narration from a 
long shot, the closed set, the setting of the film character in front of the camera, the gaze of the speaker directed at the camera lens.

There is no need for specially-prepared or additional effects. The audiovisual notes are maintained in this convention limiting the influence of film techniques to the absolute minimum. The generallyaccepted conventions determine in a fundamental way how these forms are accepted. One can observe the paradox of the mechanism of creating meaning: the less obvious film techniques are used, the greater impression they make on the viewer. This is one of the possible forms of functional justification which has been tried and tested in thousands of recorded materials. This doesn't mean, however, that they limit other possibilities in any way.

The less oriented the receiver is, the more images he needs to fully understand and experience the story being told. Even the most shocking message recorded on film verbally describing the drama of survival and daily struggle for survival does not have to stop at the personal narrative on camera. These accounts do not exclude the use of other images (archival film materials, photographs, documents, etc.) which allow the full realization and communicatioon of a given story. Our interest in a specific group of films about Holocaust survivors is not limited to the process of filming the accounts of the persons speaking into the camera. The accounts of the heroes are supplemented with archival film materials which is a process often used, and rightly so.

The analysis does not end here. A vital part of this study is the paradoxical function of these materials. If we speak of existing images of life in the ghetto under Nazi occupation, there is no such thing as a Jewish perspective in the filming of the fate of the victims. There are a few collections of amateur photographs from the Litzmannstadt Ghetto taken by Henryk Ross and Mendel Grossman, at enormous risk to their own lives. However, when it comes to moving pictures, they belong solely to the oppressors - films recorded by the Germans in the occupied countries. It also needs to be added that - while they were filmed by the Germans - this is not a collection of films which are totally homogenous.

One group of collections are official films, that is, films made in the years 1939-1943 on the order of Hitler's Propaganda Minister, recording the life in the ghettos in various occassions by German chroniclers. From the point of view of the occupiers, the subject is, at best, marginal, thus not many of them were filmed. These pictures were aimed to show the normality of everyday life in the ghettos, and to present the efficiency - even in a difficult terrain that is the General Governorship - of German civil and military administration in everyday affairs. A separate case among the official recordings are the pictures and film materials documenting the pacification of the ghetto in the spring uprising of 1943, made by soldiers of the propaganda com-

Pictures Added 
pany (Propaganda Kompanie 689) which is part of the division led by Warsaw Ghetto executioner, SS General Jürgen Stroop.

A second group of materials consist of a considerable number of private films and amateur movies filmed by civilian and military officers of the Third Reich visiting Warsaw and Łódź and the ghettos during the German occupation. The motive of these representatives of "higher culture" was curiosity tied with a peculiar whim of this race of übermensch to get to know - in the German language there is a special term for this - Armeleutegeruch (the stink of misery). Naked, skeletal corpses of those who starved to death are passed with indifference by pedestrians. The films represent the gaze of the superior man - cold, indifferent, "folkloristic".

The impunity of film. One can see that the recorders of these scenes treated the starving, skeletal and miserable residents of the Jewish district as the "natives" or "savages", existing beyond culture and civilization. The ghetto on the other hand is seen as an object of local exotica and believed to be a „tourist attraction” where filming required a separate permit from the one needed to visit the area within the high, barb-wired, strictly-guarded walls. It also happened that executioners who had a film camera were exceptionally vile, cruel and barbaric in their treatment of victims of extermination. A particularly gruesome instance is a pornographic film made in the Warsaw Ghetto with the participation of naked Jewish girls and old men who were forced, under threat of death, to take part in this monstrous spectacle for the camera.

German documentary films on the Jewish theme produced in the years 1939-1943 - whether professional recordings under the emblem of Deutsche Wochenschau (film reporters of the Propaganda Kompanie 689) ordered by the Reichspropagandasministerium from the initiative of Joseph Goebbels, or private recordings of amateur film-makers - succeeded in preserving and documenting the realities of war, while basically aiming to hint at and suggest justifications for Jewish extermination. It is worth noting the deeper connections tying the themes of many amateur films with the infamous "documentary" of Fritz Hippler. Based on a screenplay by Eberhard Taubert, Der ewige Jude (1940) is known by each German who lived through the Third Reich. Screened repeatedly in cinemas across Germany, the film became the model for how a German should think about Jews and how a loyal German should act towards them. It can be assumed that the amateur "documentalists" often followed the examples of its predecessor-guide, assuming its hateful stance and attempting to maximally dehumanize their film subjects - the residents of the ghetto.

The Nazi films of the Holocaust were made with different intentions but - despite original motives - after the war they became documentaries sensu stricto. They became extremely clear testimonies in the charge of genocide against Germany. The triumph of the victorious and their feeling of absolute superiority over a degraded and exter- 
minated nation is seen in practically every single frame. These terrible images from the Holocaust and their effective integration with modern images in films of Holocaust survivors makes a great impression on the viewer.

This impression is greater the more the viewer is aware of the change in the relevance of the material as it is used in the new context. The contempt, domination, sense of impunity, odium and total disdain on the part of the oppressors unexpectedly turn into something unintended and ironic in its message. Instead, the images elicit mercy and sympathy towards the misfortune and unspeakable suffering of the unnamed Jews in the films. What was supposed to degrade, debase and demean the victim, and justify their mass extermination in the eyes of the viewer, today accuse, discredit and dishonour the filmmakers.

The fullest expression of this basic transformation in the film materials from propaganda to accusation is, in my opinion, Kronika powstania $w$ getcie warszawskim wg Marka Edelmana (Chronicles of the Warsaw Ghetto Uprising according Marek Edelman). Its author (and at the same time cinematographer) - Jolanta Dylewska achieves this effect thanks to the creative use of the technique repollero as well as a slightly reduced tempo of the German films. These techniques (avid followers of cinematic doctrines would recognize them as techniques of manipulation) allow one to recognize the faces in the anonymous crowds, to note their specific expressions, to perceive otherwise unobservable details, realities, microsituations, human behavior, interactions between the executioners and their victims. The materials prepared by the Nazi filmmakers are unexpectedly revealed of their latent meaning. As background to the accounts of the main hero, Marek Edelman, the images in the new context speak with surprising strength in the hidden expressions, which was absolutely not the intension of those who originally recorded them.

The truth about the mechanisms of the Holocaust and the crimes committed by the Nazi death industry is not widely known today. In the years between 1944-1945, as the Eastern and Western Fronts were nearing Berlin, a considerable number of documentary films on the subject were made. They were made by chroniclers of the armies of the front - Polish, Soviet, American and British: Forbert, Samucewicz, Bossak, Karmen, Stevens and many others. They recorded these films during marches to the fronts as they come across death camps or mass graves. One such recording is that made by American soldiers who uncovered a mass grave in Southern Czech and was later used in the film Ocalona pamięta (A Survivor Remembers). Today, these films are testimonies of inestimable value.

A half-century has passed since those times, however. The films of the war documentalists are kept in archives spread all over the world and are inaccessible to common viewers. That filmmakers, among

Microhistory as a Testimony to the Truth 
them Polish filmmakers, have used them from time to time does not change the fact that they are not readily available not only in cinemas, but on television as well. It is not unusual that heads of television stations, repulsed by the idea of showing macabre images depicting the awful cruelty of Nazism and the mass crimes of the Holocaust, would withhold their transmission on air.

The result of this long-term reticence on the Holocaust among commercial mass media is well-known. With the passage of time, historical knowledge on the mass extermination of Jews, Gypsies, Poles, Russians and other nations of Europe committed by Nazi Germany in occupied Poland is becoming more scanty and misleading. In its place is widespread obtuseness, apathy and collective ignorance. How can millions of ordinary citizens in Europe and abroad be expected to be more discerning when journalists from the most influential Western media, including The New York Times, or when editors of encyclopedias published in the West had, until recently, written articles mentioning "Polish death camps"? These particular types of "mistakes" and falsification of historical truth are especially telling as the phrasing comes not from the Americans, the English, or the French, but from the Germans, who are perfectfly aware who created the gas chambers and who built the death factories where millions of people were murdered. They cannot pass the responsibility of the Third Reich for the crimes committed by the Nazis to anyone else, and yet... The most recent of these acts of falsification came from 2010. At the end of July 2010 the Polish Embassy in Berlin sent a letter of protest to the editor of the German weekly "Focus" after the publication of information regarding the Dortmund court cases against concentration camp executioners in which the phrase "Polish death camp in Bełżec" was found. The editors expressed their regret but refused to publish a rectification nor did they apologize for the blatant error. It ended with a letter from one of the Polish-German organizations published in the following issue of the magazine.

The typical reaction of those who are caught in an evident lie about the past is apparent surprise - they don't find guilt in thier actions, they affect innocence, claiming that they do not see the problem and are inclined to recognize the term as simply "politically incorrect" and suggesting that the protest attests to the "hypersensitivity" of Poles towards history.

Historical memory is not constant, unchanging, and determined once and for all. In the process of transformation the collective consciousness of historical memory and amnesia wage with each other an unending struggle. In this sense, the disappearance of memory in society is worse than lies. The falsification of history can be contradicted by appealing to the facts, if we are equipped with irrefutable arguments in the form of the testimony of someone who was personally involved in the event, a witness who remembers. Memory loss towards historical events is unusually dangerous as it feeds ignorance. 
It discards the worth of the truth of everything that had passed, opening the gates to the falsification of history, including Holocaust denial.

The documentary and historical importance of the film materials made by the allied forces at the end of the war about the death camps and the unprecedented scale of the crimes committed by the Nazis is difficult to judge. One can note however that - in terms of the style peculiar to these films, the distressing method of depicting war and the narration of it - they belong more to the greater macrohistorical narrative on the Second World War rather than the filmography of Holocaust documentaries. The propagandist soundbytes in the films determine their style and the role that they played in movie circles. In this sense these pictures - as a report on the Holocaust - remain suburdinate to other aims.

What's worse, the impersonal modus of narration used in these films give the impression that the immensity of the atrocities of the Holocaust is expressed in a tone that is cold and indifferent in its description as seen through the panoramic gaze of the camera as well as the eloquence of the terrifyingly huge numbers, heard offscreen as read by the unseen voiceover. The tone of these materials is dominated by a generalized perspective resulting from the outsider's viewpoint of an anonimous narrator. This de-personalizes the account, paradoxically removing from it what ought to be paramount: the perspective on this awful tragedy of the individual who is a victim of Nazism. The death camps and the exterminations conducted there are changed in these impersonal documentaries into indifferent abstractions - a sequence of macabre images which cannot directly engage the modern viewer.

The opportunity for a different perspective came with the personalization of news information at around the end of the 20th century, half a century after the end of the war. This also significantly changed the cinematic interpretation of the Holocaust. It took a substantial amount of time for film and television to learn how to speak differently about crimes against humanity. That is, the truth about them could be uncovered only when the viewer is confronted not by the abstraction of an unimaginable number of victims, not by the ideologized, instrumental, mythical treatment of the Holocaust, but by the personal experience of the witness who survived.

Keeping the continuity of historical memory, untiringly renewed and passed on to the new generation, is something especially necessary and crucial. Steven Spielberg, who was born after the war, in deciding to finance the creation of the Survivors of the Shoah Visual History Foundation, had a particularly keen awareness that collective memory quickly fades and disappears, and its maintenance requires a strong and lasting support. The global impetus and wide scale enterprise that was set into motion by this unique project - underappreciated, but worthy of the highest esteem - could be seen in the fact that in the years 1994-1995 alone around 52 thou- 
sand documentary records were filmed in 56 countries and in 32 languages.

Marcel Łoziński used four such accounts from among many thousands in the film Pamiętam (I Remember) complementing them with a compositional frame in the form of a leitmotif composed of short scenes lasting several seconds from the March of the Living through the former concentration camp Auschwitz-Birkenau. These images were edited to fuse into each other or into other images. They are not incidental to the narrative aired onscreen. The editing by Katarzyna Maciejko-Kowalczyk is a work of exceptional precision and logic and carefully thought out in the smallest details.

Let us take for example a fragment from the accounts of Henryk Mandelbaum on the concentration camps. In the scene where he speaks about the maltreatment of the people transported to the camps in cattle wagons, on the screen we see mirror images in the form of modern takes of the railway tracks in Oświęcim and a present-day crowd of young people heading towards us from the ramps of the camp. Another account by Mandelbaum about a dramatic story filled with hope for the possibility of rescue which unfortunately ended with death begins with a scene of the attentive and enthralled faces of young modern Jews, participants of the March of the Living and ends with the news of the hero's death and the image of the viewers - their heads hanging and eyes fixed on the floor - motionless and grave.

This is not a technique which is singular or occassional. In all four narratives of Pamiętam short takes on modern society are used regularly as counterpoints in specific accounts. The common goal of these noble mergings of images and the accents provided by the music (the glissando of violins enhanced by the sound of cellos) is an intentional arrangement designed to attain the desired reaction towards the film. It serves to achieve maximum focus and attention. It is about activating empathy through the behavior and "inner" reaction of the viewers, particularly those young people visiting the terrain of the camp in Oświęcim. Their focused and silent faces, the glances and inidividual reactions are chosen in such a way as to function as countertakes to the dialogue with the figures of the four narrrators. At the moment that they appear onscreen, the narrative continues undisturbed, the voice heard offscreen. All of these serve to arouse sympathy, maximally focusing attention on the dramatic accounts of an old man saved from the Holocaust.

The composition of the film Pamiętam exemplifies in a particularly expressive way the more general model of the poetics developed by the authors of the series of documentaries about survivors. A basic element of their construction is the onscreen narration of each of its four Holocaust survivors, filmed against a neutral background following the canon of archival documents in the foundation of Spielberg. The creative development of this formula is enriched by fragments from modern or current films. The documentary is opened by a series 
of images from the March of the Living, accented by the image of the famous gates of the Auschwitz concentration camp with the words "Arbeit macht frei”. The film ends with the touching scenes of Pope John Paul II at the Wailing Wall in Jerusalem and of two young people, heads nestled together, shaken by what they had seen in Auschwitz. This is the frame of composition of the entire work - a prologue and an epilogue surrounding its narratives. This technique does not only determine the course of the film, raising it to an artistic, composed whole, but it also allows the film to build a symbolic bridge between the painful past of the terrible 20th century hecatombs and the present day.

None of the given microhistories represented in the documentaries of Marcel Łoziński (or in those of other documentaries) can fully depict the collective tragedy that occurred. And this is not their goal. Each of the four narratives is different. They differ in the style of narration, in the individual perspective of the narrator, the setting of the action and the diversity of personal experience. The stoker of corpses in the Sonderkommando in KL Auschwitz, Henryk Mandelbaum was already a grown man at the time when Piotruś Szereszewski, a red-headed boy from the Warsaw Ghetto (as narrated by Stanisław Jonas), was switched over to the Aryan side by tram dressed in the uniform of a Hitlerjugend. Dawid Efrati smuggled provisions to the Warsaw Ghetto and went there to watch tragedies performed by the most prominent Jewish actors, while at that time the boy Leszek Allerhand was hiding for months in Lwów under the bed of a German prostitute.

Each of these screen narratives, each of these microhistories described by the heroes, has a fragmentary dimension, with no pretensions to any kind of sweeping universality. But their fragmentary nature (similar to the role of a single tile in a mosaic) is their strength, not their weakness. They serve as witnesses - individually and together as a whole - for themselves and for other narratives which could not be told. This is the motto of the film Ocalona pamięta (A Survivor Remembers): "A tribute paid to the millions whose stories could not be told."

Kronika powstania $w$ getcie warszawskim wg Marka Edelmana

(Chronicles of the Warsaw Ghetto Uprising according to Marek

Edelman). Director: Jolanta Dylewska. Cinematography:

Jolanta Dylewska. Production: Studio Filmowe Logos and

Wytwórnia Filmów Dokumentalnych i Fabularnych, 1993.

Ocalona pamięta. (One Survivor Remembers). Director: Kary

Antholis. Cinematography: Andrzej Jeziorek, Erich Roland.

Production: Home Box Office with United States Holocaust

Memorial Museum and Wentworth Films, Inc., 1995.

Pamiętam (I Remember). Director: Marcel Łoziński. Cinematogra-

phy: Andrzej Adamczak (Marsz Żywych, March of the Living)

Filmography 
and Jacek Knopp as well as Piotr Augustynek, Yitzhak Gol, Jerzy Tabor, Robert Raplewski. Production: The Shoah Foundation oraz Heritage Films, 2001.

Wyspa Getto (The Ghetto Island). Director: Ewa Żmigrodzka, Krzysztof Zwoliński. Cinematography: Ryszard Janowski, Mikołaj Nesterowicz. Production: Agencja Produkcji Audycji Telewizyjnych for Polish Television, 2003.

Portrecista (The Portraitist). Director: Ireneusz Dobrowolski.

Cinematography: Jacek Tuszakowski. Production: Grupa

Filmowa Rekontrplan for Polish Television, 2005.

Chłopak i dziewczyna (A Boy and a Girl). Director: Sławomir

Koehler. Cinematography: Tomasz Samosionek, Piotr

Wejchert, Karol Kostrzewski. Production: Media Kontakt for Polish Television, 2005.

Radegast. Director: Borys Lankosz. Cinematography: Borys Lankosz, Karolina Pająk, Aleksander Ostrogski. Production: Grupa

Filmowa Fargo for Polish Television, 2008.

In Gratitude

I would like to express my heartfelt gratitude to the individuals who provided support in the research and writing process of this paper: Jadwiga Hučkova, Agata Makohin, Katarzyna Malinowska, Katarzyna Mąka-Malatyńska, Wojciech Diduszko and Mikołaj Jazdon.

Trans. by Jo-Ann Budzyńska 